\title{
Development of Scientific Publications on Acupuncture
}

\author{
Jenny-Ann Brodin Danell and Rickard Danell \\ Department of Sociology, Umeå University \\ Sweden
}

\section{Introduction}

During the last couple of decades, the use of acupuncture, in order to treat and relieve different kinds of symptoms and disorders, has increased dramatically in Western societies (e.g., Eisenberg et al., 1993; Harris \& Rees 2000; Thomas et al. 2001; Vincent \& Furnham, 1996). Together with some other integrative and complementary therapies ${ }^{1}$, such as osteopathy and chiropractic, acupuncture has evolved from being a rather unusual treatment to a relatively accepted one, and has been integrated in public health sectors. Today, it is often possible to get acupuncture from biomedical professionals, such as doctors and midwives, or visit trained acupuncturists as part of conventional health care, which is covered by general social security systems.

Previous studies indicate a rapid increase in research of integrative and complementary medicine in general (Danell \& Danell, 2009; Fu et al., 2011) and on acupuncture (Han \& Ho, 2011). There are also indications of a growth in evidence-based research, in the form of clinical trials, in sub-fields such as acupuncture and musculoskeletal manipulations (Danell \& Danell, 2009), and increased publications in mainstream biomedical journals (Barnes et al., 1996; Fontantarosa, 2001). There has also been notable institutional and financial support for research on integrative and complementary medicine through, for example, the establishment of the National Center for Complementary and Alternative Medicine (a branch of the US National Institute of Health) and associations such as the International Society for Complementary Medicine Research.

However, the establishment of integrative and complementary medicine in biomedical contexts is far from uncontroversial. In most Western countries there are both symbolic and institutional divisions between biomedicine on one hand, and alternative/complementary/integrative medicine on the other (e.g., Jütte, 2001). One crucial

\footnotetext{
${ }^{1}$ In this chapter, we will use the concept "integrative and complementary medicine" in order to describe practices that are not currently an integral part of Western biomedicine, since this is the concept used as subject category in SCI Expanded. However, there are several other concepts - such as "complementary and alternative medicine", "holistic medicine", and "non-conventional medicine" that are used in a similar way (for a more detailed discussion on concepts see, Cant and Sharma (1999), Easthope (2003), and Gorski (1996)). In general, complementary and integrative therapies are used in addition to conventional biomedicine, while alternative counterparts are used instead of conventional treatments.
} 
aspect is that most of these traditions, at least to some extent, rely on ideas and procedures that are either in conflict with or not fully explained in relation to biomedical norms. It is far from self-evident that research on integrative and complementary therapies is accepted in biomedical research teams, published in high standard biomedical academic journals, or funded by public research foundations - even if the therapies have gained a relatively high degree of public acceptance and integration in the public health care system. One of the most crucial strategies from an integrative or complementary perspective is to engage in peer-reviewed research and, ultimately, to perform high quality clinical randomized trials (Adams, 2002).

The purpose of this chapter is to investigate the development of scientific publications, defined as documents in the Web of Science database, on acupuncture during the time period 1990-2010. What is the general publication trend over the time period? What kinds of documents are published? Are documents on acupuncture found in general biomedical journals or in specialized ones (either on integrative or complementary medicine or other biomedical sub-fields)? To what extent, if any, are the publications found in prestigious or high ranked biomedical journals? Where are highly cited documents published? Is there an increase of clinical trials on acupuncture? Where is the research conducted with regard to countries or larger regions?

\section{Data and method}

The data for this chapter is retrieved from SCI Expanded in the Web of Science database. Some parts of the analysis, as will be outlined below, is complemented by information from the PubMed database and Journals Citations Report.

To identify documents on acupuncture, we use the keywords acupunct*, acupoint*, electroacupunct*, and electro-acupunct* to search titles, abstracts, and keywords in SCI Expanded. The time period is restricted to the years 1990 to 2010, and the material is analyzed with the help of bibliometric methods.

\section{Results}

\subsection{General publication trend and types of documents}

During the time period 1990-2010, 5870 documents were published on acupuncture, according to the SCI Expanded. Overall, the publication trend can be divided into two periods (Figure 1). The first period covers the 1990s, where there was a yearly growth between 83 and 201 documents. The second period starts in the early 2000s, and is characterized by a more rapid increase of published items. During the last two years, 2009 and 2010, more than 600 documents on acupuncture were published each year.

For the whole period, the great majority of the documents ( 80 percent) are classified as Articles. About ten percent are classified as Reviews, eight percent as Letters, and less than one percent as Notes. In absolute numbers, articles and reviews have increased the most during the period (Figure 2). There are no notes at all after 1996.

However, if looking at the share of published items, the pattern is more stable (Figure 3). The share of articles varies between 77 and 85 percent, and there is no clear trend over time. In the case of reviews it is possible to identify an increase in the share of published documents, with a development from two percent at the beginning of the time period to 15 percent at the end. This increase, both in absolute numbers and in the share of all 
publications on acupuncture, can very well be a sign of the growing interest in research on acupuncture and the scientific need of overviews on particular aspects of the research-for example on the use of acupuncture in the treatment of specific disorders. It may also be a sign that acupuncture is established as a scientific sub-field.

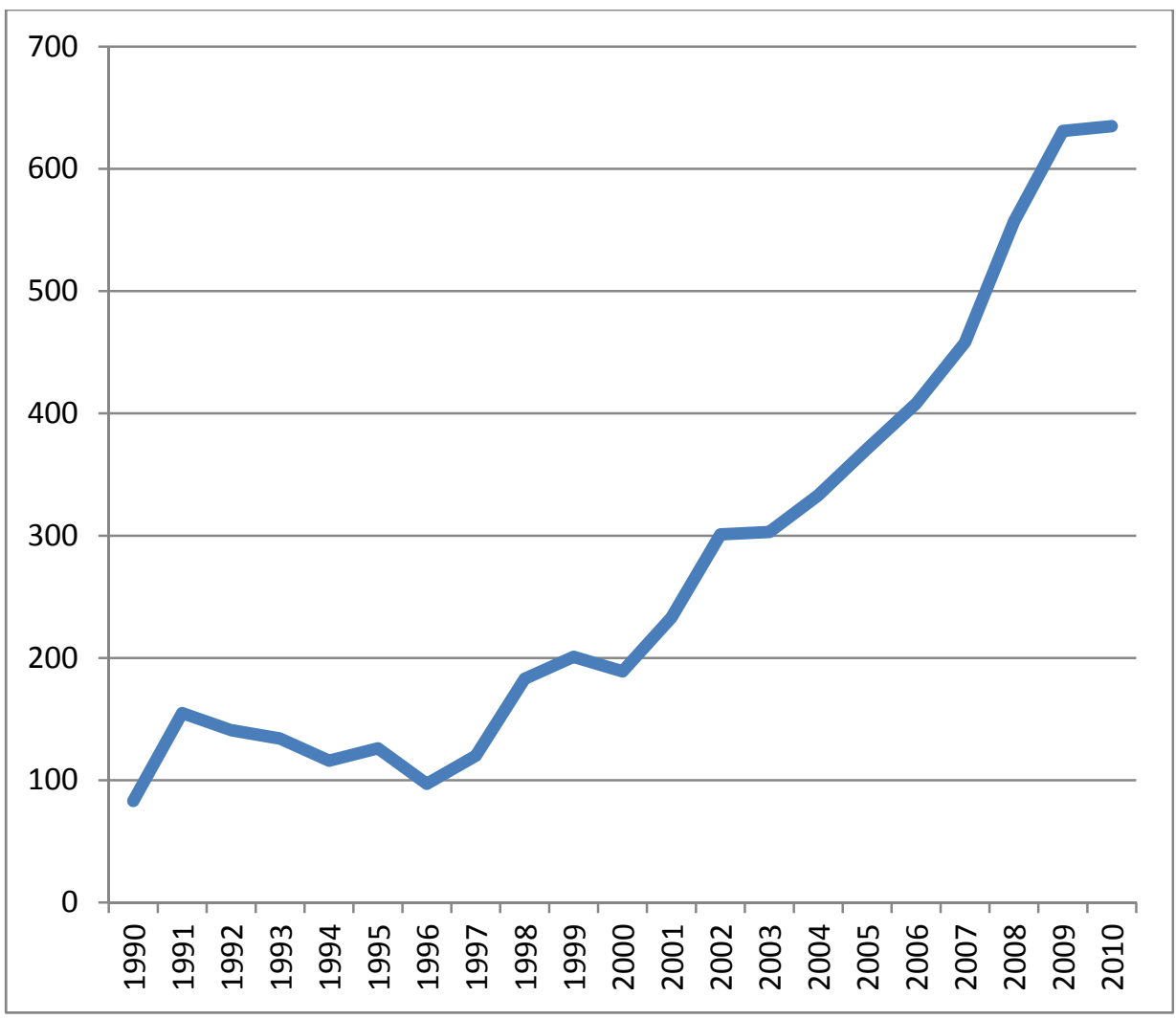

Fig. 1. Number of documents on acupuncture. 1990-2010. 


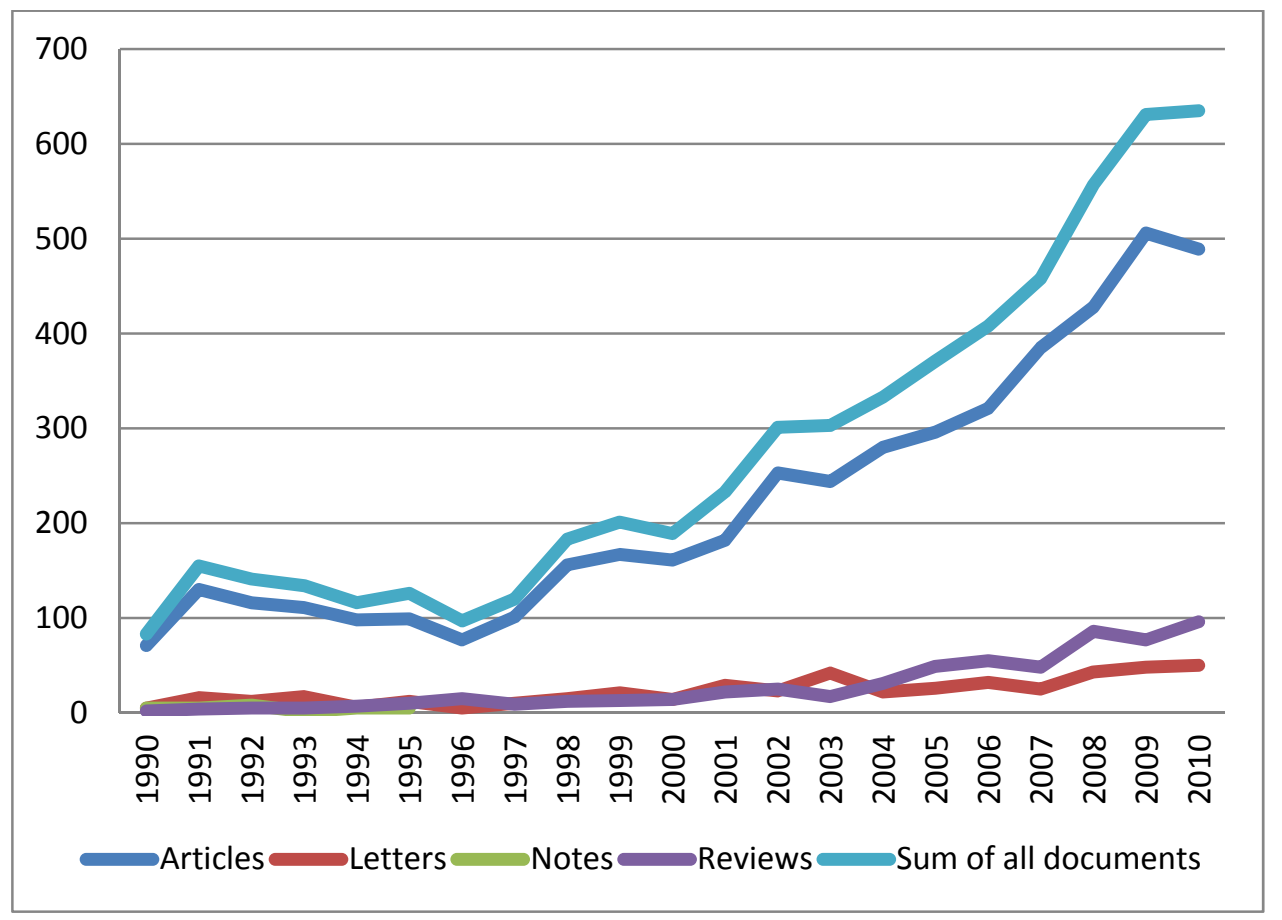

Fig. 2. Number of different types of documents on acupuncture. 1990-2010. 


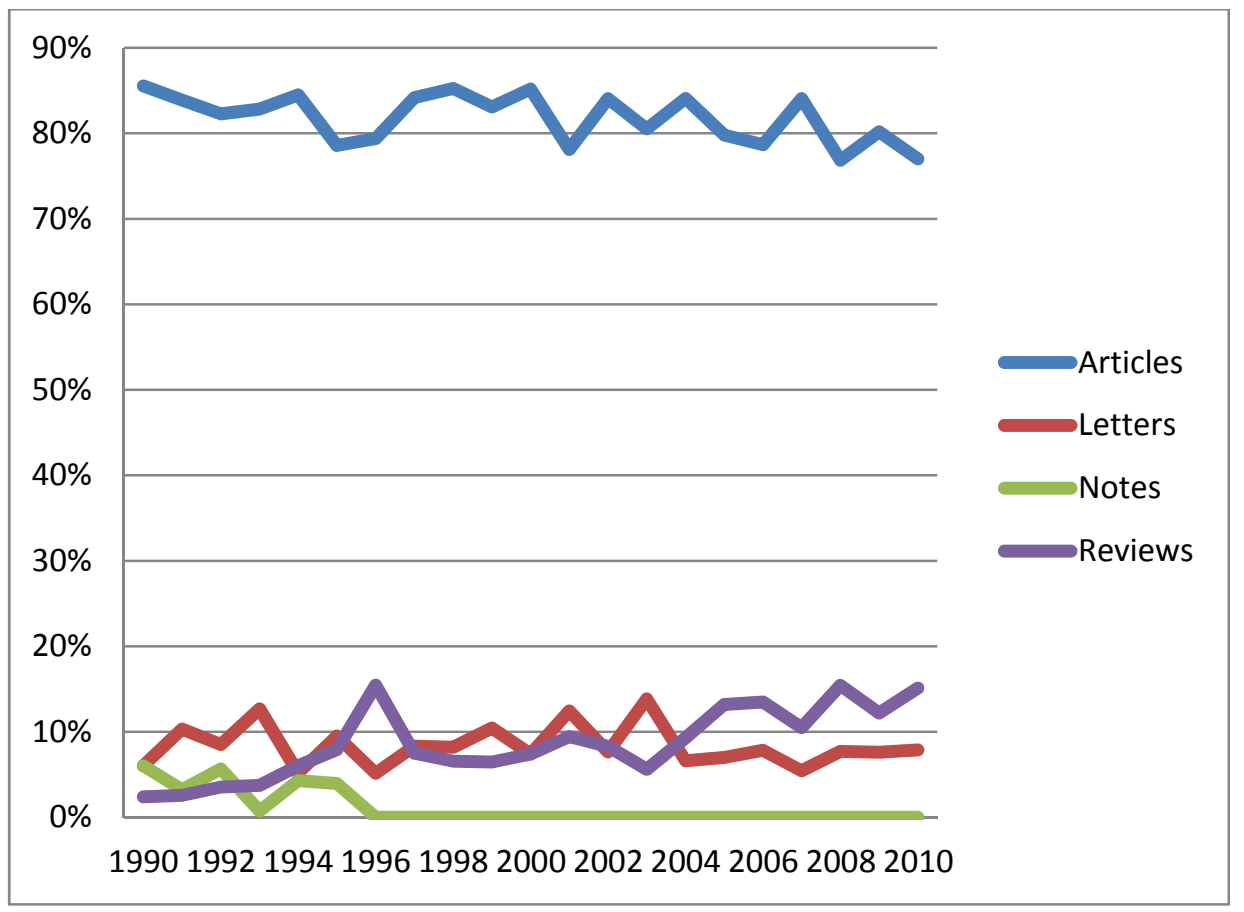

Fig. 3. Share of different types of documents on acupuncture. 1990-2010

\subsection{Academic journals}

An interesting aspect of the publication pattern is in what kind of journals the documents are published. Are documents on acupuncture found in general biomedical journals or in specialized ones (either on integrative or complementary medicine, or other biomedical subfields)? To what extent, if any, are these publications found in prestigious or high ranked biomedical journals? Where are highly cited studies published?

If we just take a look at the subject categories ${ }^{2}$ of the journals for the whole time period, we can see that the most frequent category is Integrative and Complementary Medicine, which includes 24 percent of the documents on acupuncture. In this broad category, we find general journals (such as the Journal of Alternative and Complementary Medicine and Complementary Therapies in Medicine), those specialized on acupuncture (such as Acupuncture in Medicine and Acupuncture $\mathcal{E}$ Electro-therapeutics Research), and other sub-fields (such as homeopathy). Other frequent subject categories among the journals are Clinical Neurology (nine percent), Medicine General \& Internal (nine percent), Neurosciences (seven percent), and Anesthesiology (seven percent).

To refine the results, and get a clearer picture of the development over time, we have reclassified the journals according to three broad categories: Integrative and Complementary Medicine $^{3}$, Biomedicine ${ }^{4}$ and Other ${ }^{5}$.

${ }^{2}$ According to SCI Expanded.

${ }^{3}$ Defined as journals of which one subject category is Integrative and Complementary Medicine. 
From this re-classification (Figure 4), we can see that a majority of the documents for the whole time period are published in journals classified as Biomedicine. We can also see that the publication trend within all three categories is rather similar, especially concerning a rapid growth in the 2000s.

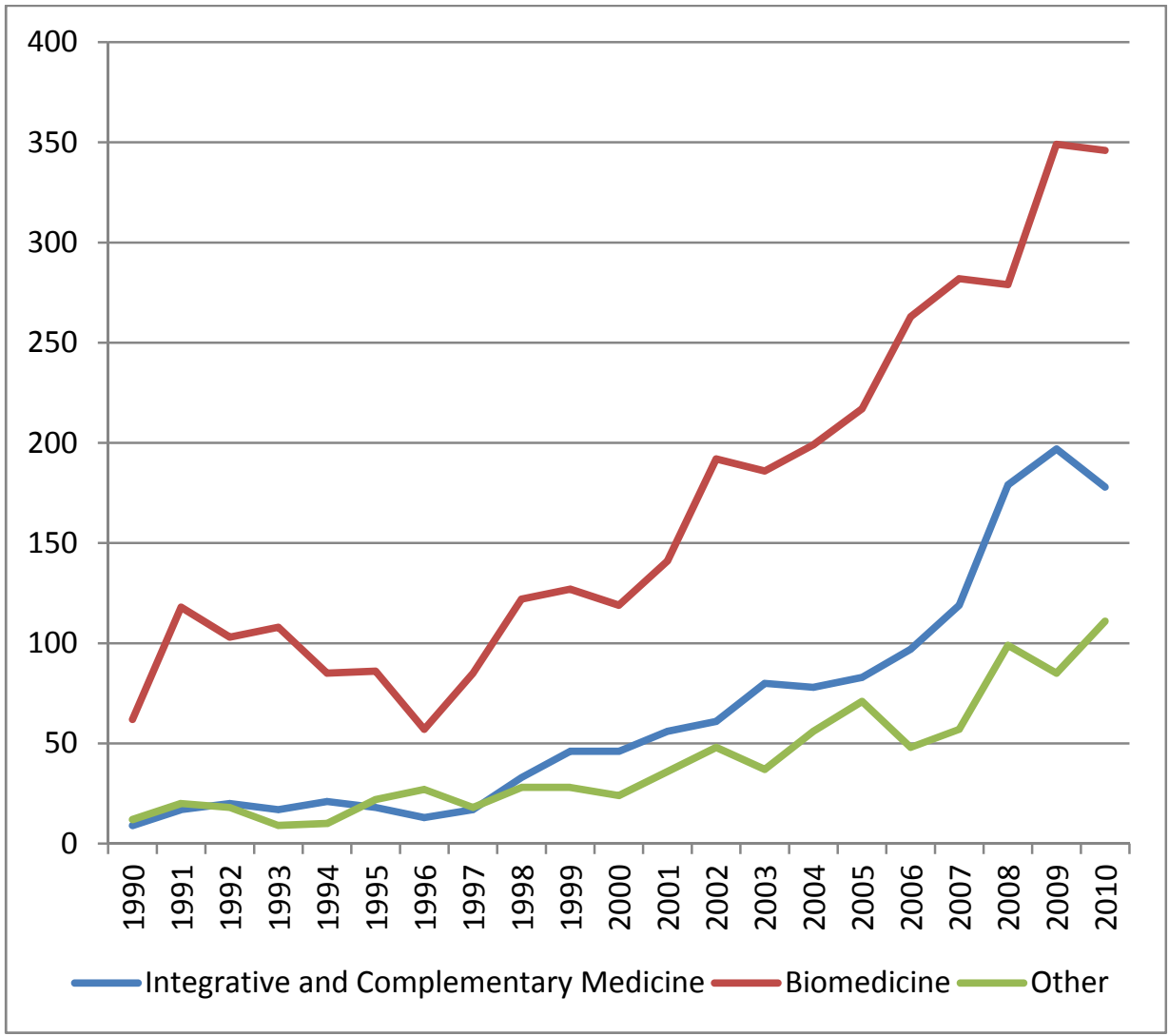

Fig. 4. Number of documents published in the journal categories Integrative and Complementary Medicine, Biomedicine and Other. 1990-2010.

${ }^{4}$ Defined as all other medical subject categories (for example, surgery, oncology, nursing, allergy, rehabilitation).

${ }^{5}$ Defined as all other subject categories (for example, material science and textile, sport science, statistics). 


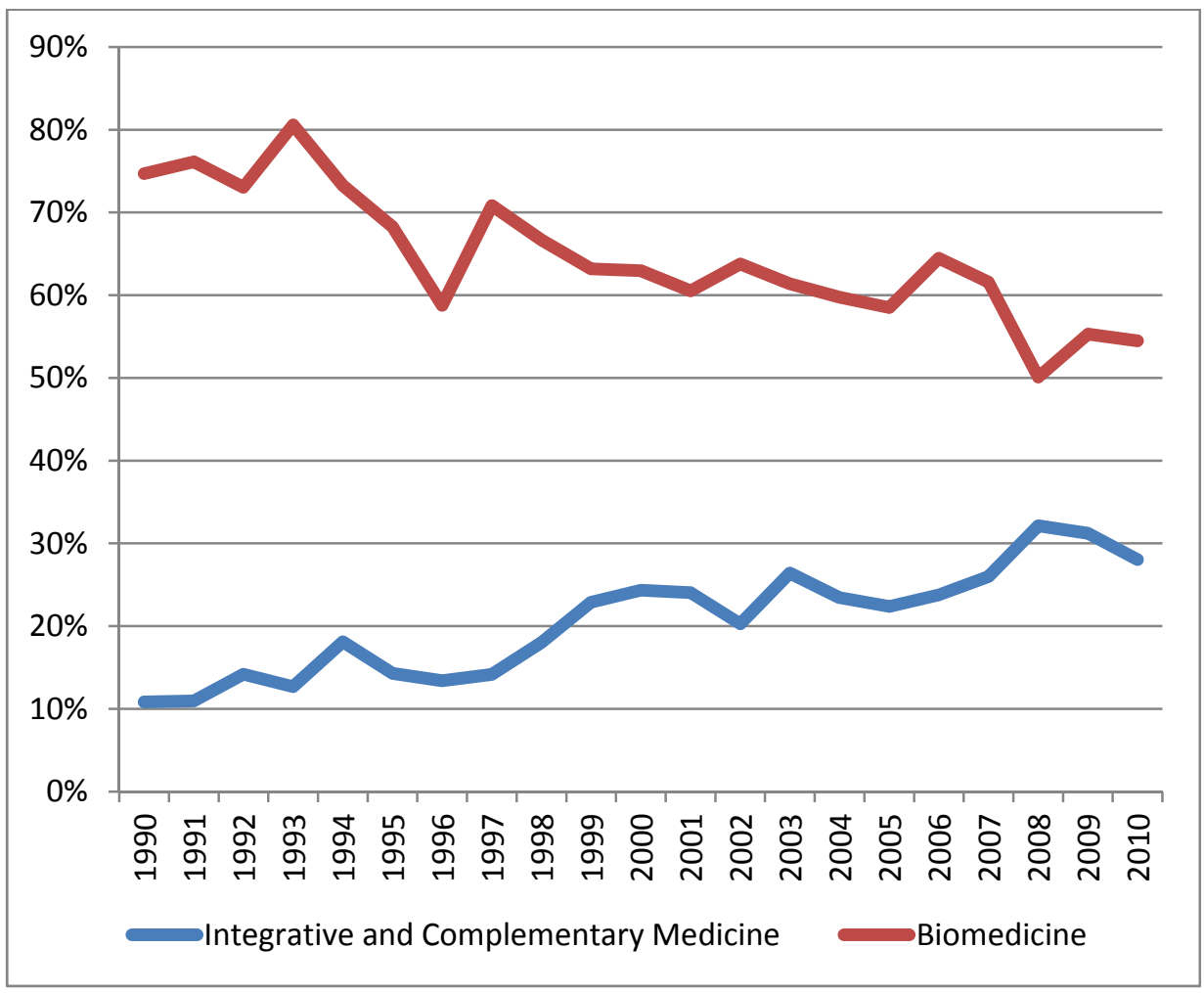

Fig. 5. Share of documents on acupuncture published in the journal categories Integrative and Complementary Medicine and Biomedicine. 1990-2010.

However, if we look at the shares of the categories in relation to all of the documents on acupuncture, we can identify another pattern (Figure 5). Publications in the category Integrative and Complementary Medicine have increased from about ten percent in 1990 to almost 30 percent in 2010. In the category Biomedicine the development shows almost the opposite. In 1990, about 75 percent of the documents were published within this broad category. In 2010, the share decreased to about 55 percent. The relatively low numbers, and small share, of documents published in the category Integrative and Complementary Medicine at the beginning of the time period can probably be explained, as indicated above, by the fact that the category has expanded during the last couple of decades, both by the establishment of new journals and by the inclusion of already existing journals in the database (cf Danell \& Danell, 2009). 
To measure to what extent the publications on acupuncture are published in prestigious biomedical journals, we have combined two measures. First, we have matched the documents with Abridged Index Medicus/Core Clinical Journals ${ }^{6}$ in PubMed, which is an index that includes both general biomedical journals and specialized ones (in areas such as anaesthesia, cancer, gynecology, neurology, and surgery). Second, we have matched the documents with the top 20 journals, according to the general impact factor, in the category Medicine General \& Internal in the Journal Citations Report. To some extent these two measures overlap, but in general the last one is more narrowly defined.

Of the 5870 documents about ten percent are published in Core Clinical Journals and about 4 percent in the top 20 category (Table 1). We can also see that these classifications overlap to some extent. Of the 588 documents published in Core Clinical Journals 137 are also found in the top 20 category. These are items published in the American Journal of Medicine, Annals of Internal Medicine, Archives of Internal Medicine, British Medical Journal, Lancet, and MAYO Clinic Proceeding.

\begin{tabular}{lrrr} 
& Other journals & Top 20 & Sum of documents \\
\hline Core Clinical Journals & 451 & 137 & 588 \\
Other journals & 5160 & 122 & 5282 \\
\hline Sum of documents & $\mathbf{5 6 1 1}$ & $\mathbf{2 5 9}$ & $\mathbf{5 8 7 0}$
\end{tabular}

Table 1. Classification of documents due to the categories Core Clinical Journals, Top 20 journals and Other journals.

If one looks at the absolute numbers of publications within the categories Core Clinical Journals and the top 20 journals, there is a clear increase over the time period (Figure 6). In 1990, it was only 4 and 2 published items in each category, respectively. At the end of the period, there were 32 and 17 items, respectively. The peak was in 2007, when 50 documents were published in Core Clinical Journals.

However, if we compare the publications within these to two categories with the general publication trend, another pattern becomes visible. In Figure 7, we show the share of published items in Core Clinical Journals and top 20 journals in relation to all of the documents on acupuncture for each year. Even if one should not overestimate variations between specific years, because of the low numbers, there is a peak in publications in both categories in the middle of the time period. It is also possible to identify a decrease in both categories during the last couple of years.

Of the 20 most cited documents eight are found in Core Clinical Journals and six in the top 20 category (four of the documents are found in both categories). Only one of these documents (Thomas et al., 2001) is published in a journal that focuses on integrative and alternative medicine (Complementary Therapies in Medicine). The rest are found in general journals (such as Proceedings of the National Academy of Sciences of the United States of America) or in specialized ones (such as Pain, Journal of Clinical Oncology, and European Journal of Pain). An interesting aspect of the highly cited documents on acupuncture is that only two of them are classified as clinical trials. Most of them include different kinds of reviews, recommendations or surveys.

${ }^{6}$ The latest version is from August 2010 and includes 119 journals. 


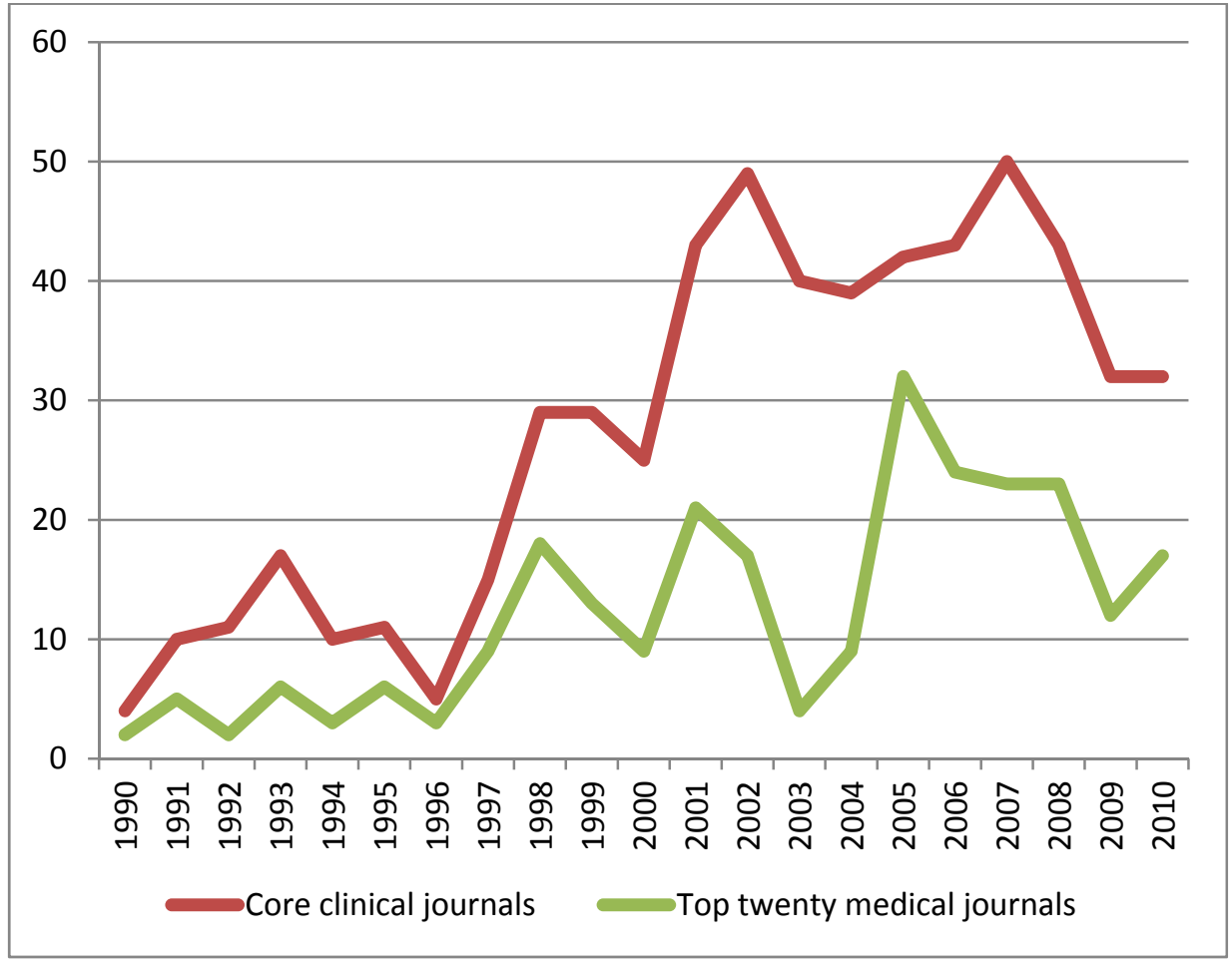

Fig. 6. Number of documents published in Core Clinical Journals and Top 20 journals. 19902010. 


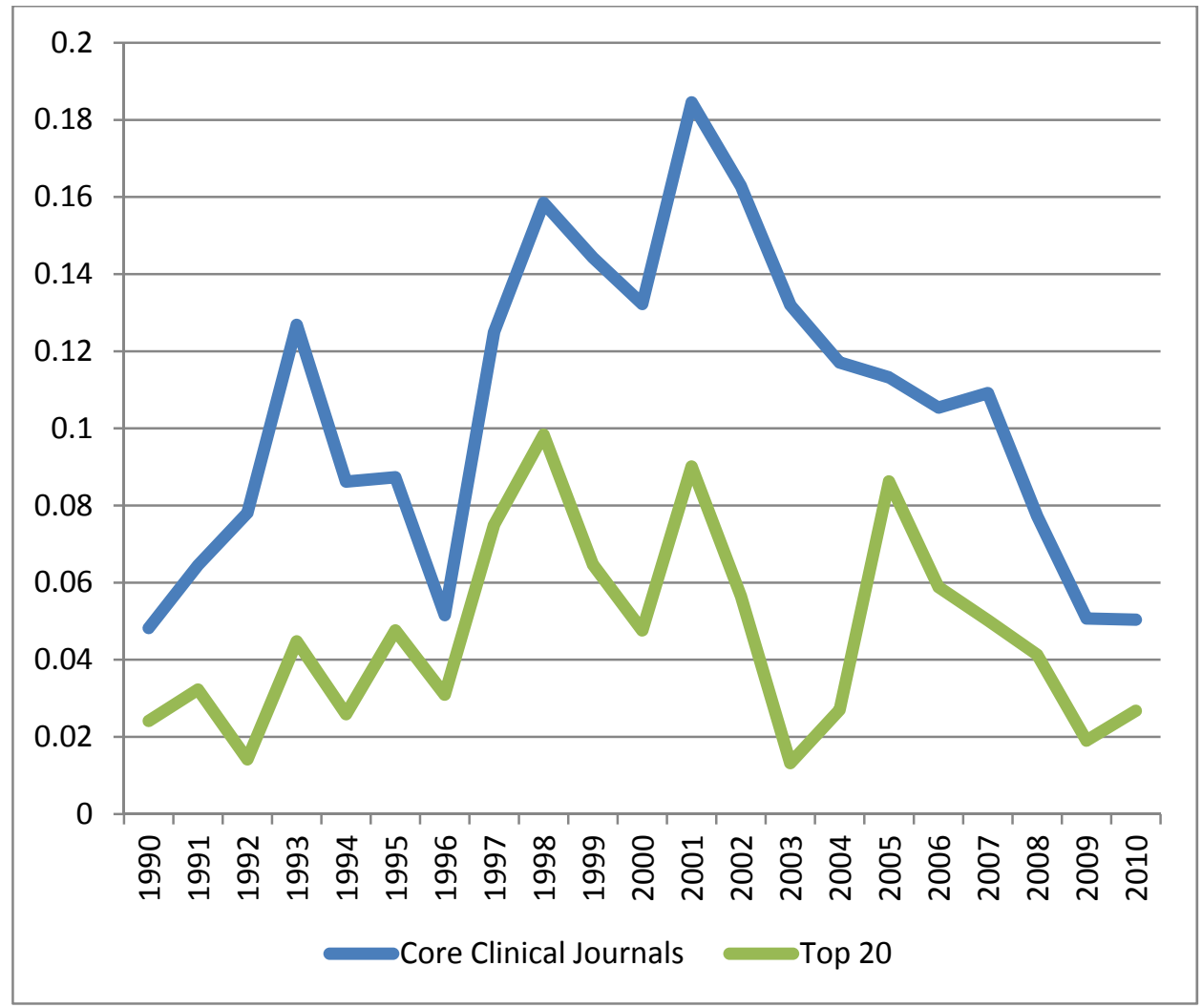

Fig. 7. Share of documents published in Core Clinical Journals and Top 20 journals in relation to all documents on acupuncture. 1990-2010.

\subsection{Clinical trials}

As mentioned in the introduction, one of the most crucial strategies to achieve legitimacy in biomedical contexts is to engage in evidence-based research, especially in the form of high quality clinical trials. Since there is no information on whether a document includes a clinical trial or not in SCI Expanded, we have matched the documents with the PubMed database according to full title. From this search procedure we found about 800 documents classified as clinical trials. Since this kind of classification is seldom perfect, we have also searched the titles of the 5870 documents for the expression "clinical trial". From this procedure we added 20 more documents, which can be classified as some kind of clinical trial. In total, we found 814 clinical trials on acupuncture during the time period 1990-2010. If we start with the absolute numbers, we can see that there were very few clinical trials published on acupuncture in the early 1990s (Figure 8a). In 1990, there were only four, and at the end of the decade there were 26. At the end of the 1990s, there was a small but steady increase, a development that has been accentuated in the last 10 years. The years 2009 and 2010 specifically stand out with 117 and 116 clinical trials on acupuncture, respectively. Most of these studies are not classified according to phases. Only four are classified 
according to phase I (Singh et al., 2008; Mazetto et al., 2007; Kim et al., 2004; Zeltzer et al., 2002), and another four according to phase II (Beer et al., 2010; Lansdown et al., 2009; Vickers et al., 2004; Wong et al., 2003).

A relevant question is if this growth is larger than the general increase of published items on acupuncture? If we compare the share of documents classified as clinical trials with all other documents, we can identify a clear increase in the first category (Figure 8b). In the early 1990s, between two and five percent of the yearly publications on acupuncture were classified as clinical trials. At the end of the period the share is 18-19 percent.

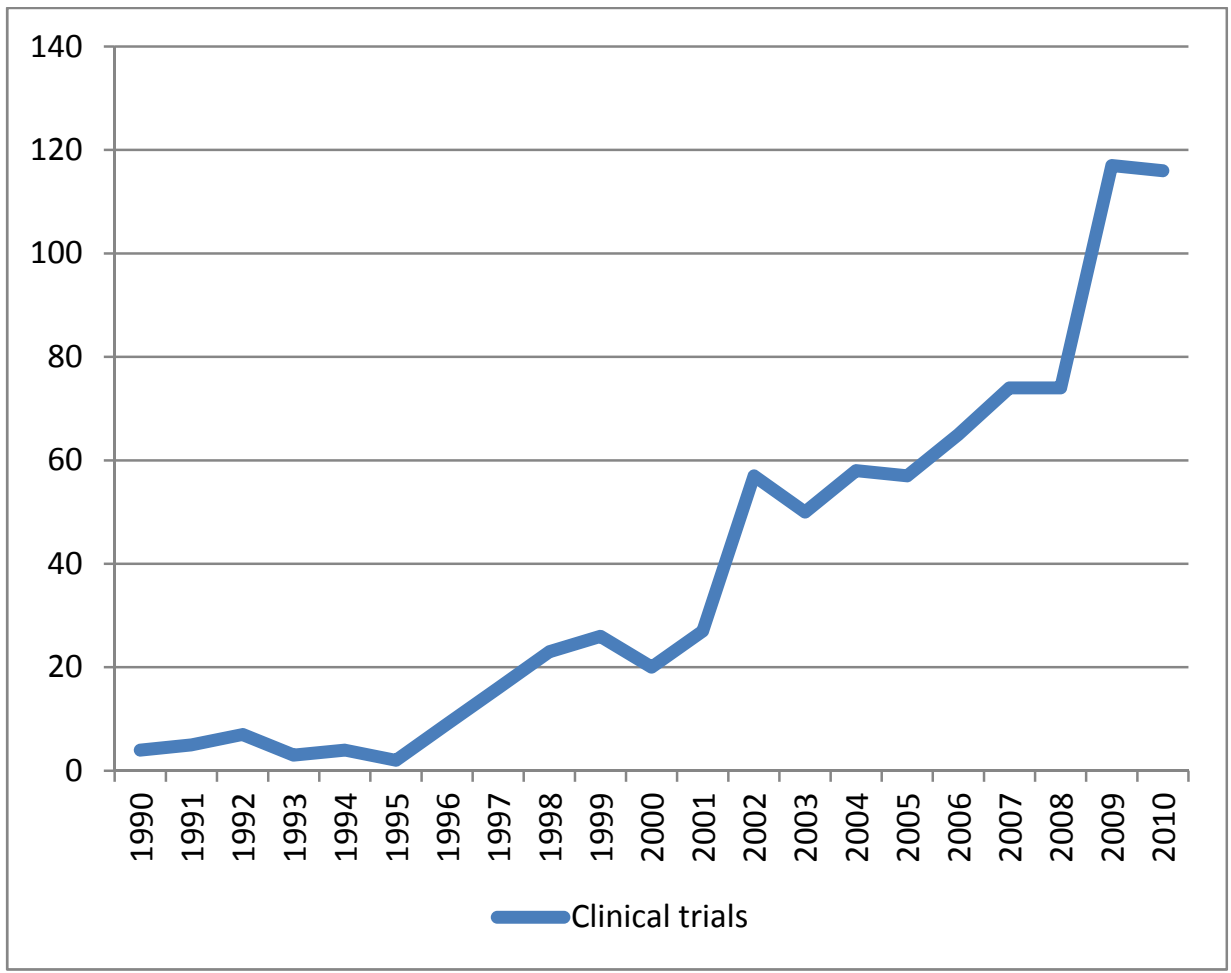

Fig. 8a. Number of clinical trials on acupuncture. 1990-2010. 


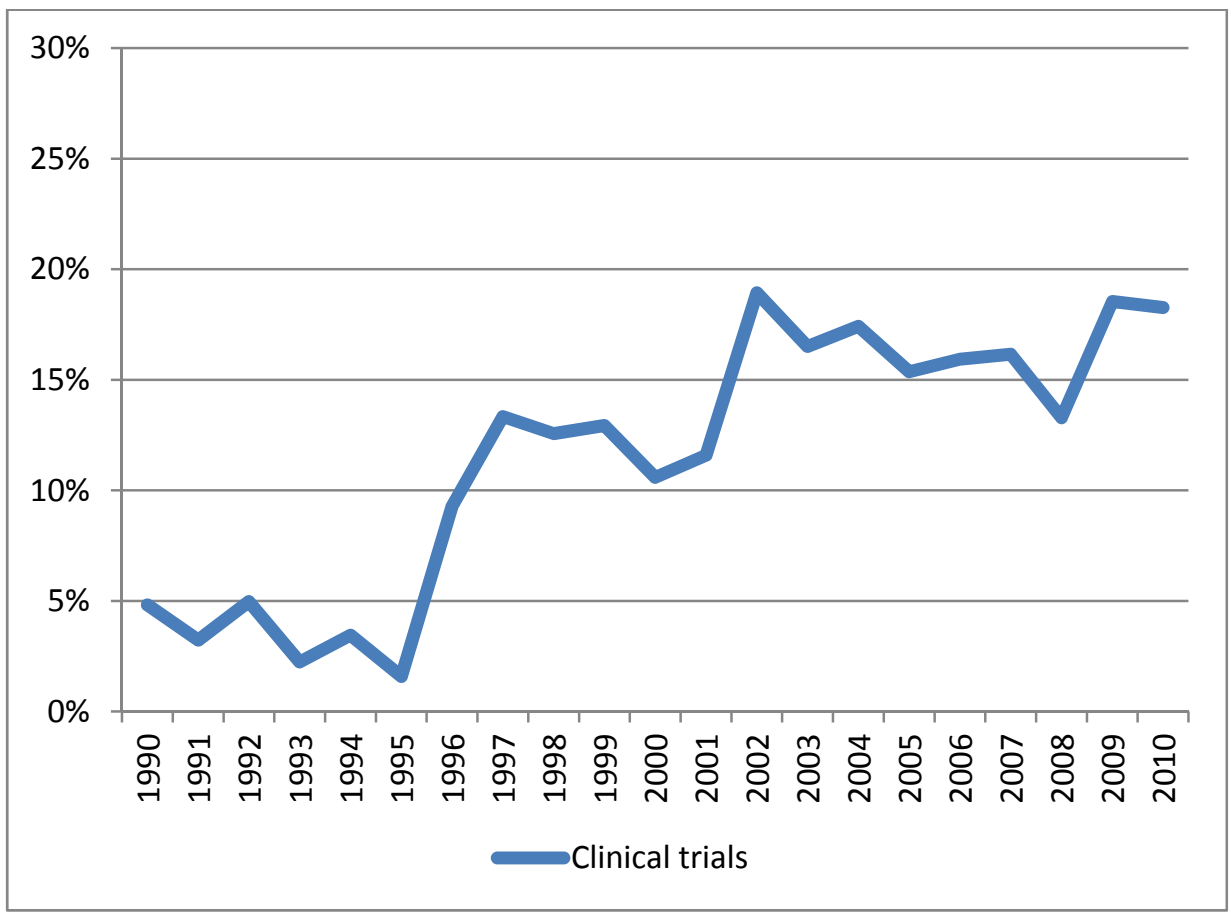

Fig. 8b. Share of clinical trials in relation to all documents on acupuncture. 1990-2010.

\subsection{Countries and regions}

In order to grasp where the research is conducted, we have fractionalized the addresses of the authors of the documents. This means that if there are two authors on one article, one from the US and one from Japan, each country will get 0.5 in value for the publication.

If we start with an overview for the whole time period, the greatest share of publication is from the US ( 25 percent), followed by the People's Republic of China (14 percent), the United Kingdom (nine percent), Germany (seven percent), and South Korea (seven percent). The US is also dominating in the publication of clinical trials on acupuncture with 167 for the whole time period, which can be compared with 97 from China, 53 from the United Kingdom, 69 from Germany, and 53 from South Korea. However, if we add the development over time, another pattern also becomes visible (Figure 9). The increase of publications set off earlier in the US, in the late 1990s, than in China and South Korea. During the last two years, there has also been a shift in that China now has more publications on acupuncture each year than the US. 
To obtain a complementary view of the development over the time period, we have re-classified all countries included in the material according to four larger regions: Asia, the European Union, North America, and Other countries (Figure 10). From this it is clear that the increase in the publication activity in Asia has been rapid, especially during the last couple of years. Furthermore, this region is now dominating. From this categorization, the development in North America and in the European Union is more similar than what is obvious when looking at individual countries.

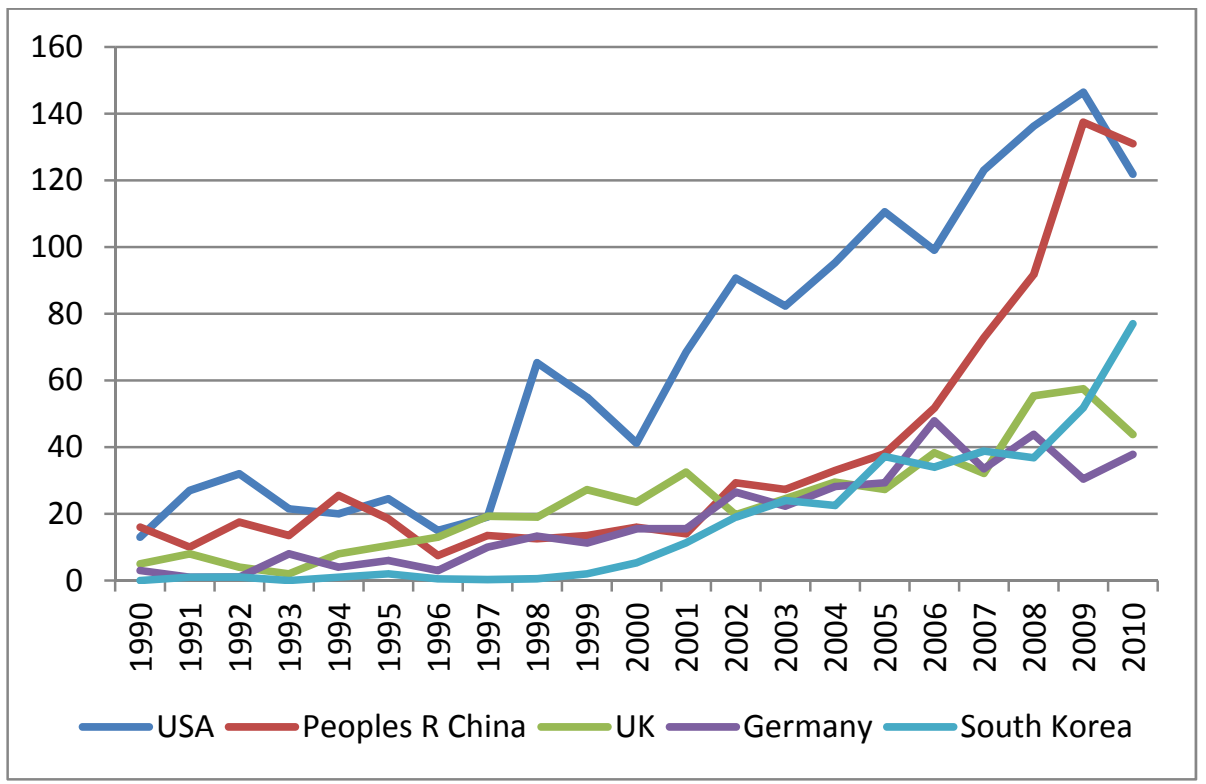

Fig. 9. Number of publications on acupuncture from the US, China, the United Kingdom, Germany, and South Korea. 1990-2010. 


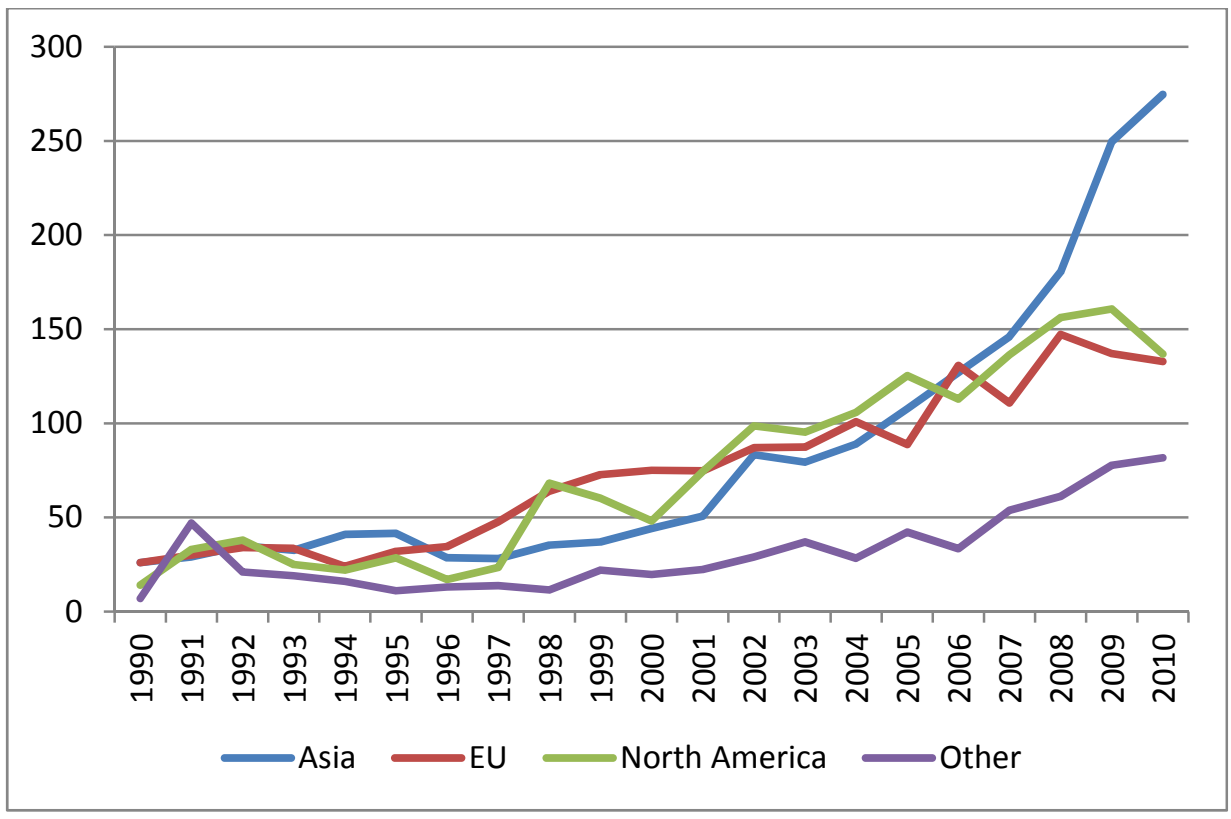

Fig. 10. Number of publications in Asia, the European Union, North America, and Other countries. 1990-2010.

\section{Conclusion}

To conclude, we can identify a dramatic increase in published documents on acupuncture, especially during the 2000s. The majority of the documents are classified as Articles, even if Reviews have increased relatively more over time. This development can very well be a consequence of the fact that research on acupuncture is becoming more established as a medical sub-field, and is in a scientific need of overviews and reviews (for example, on the use of acupuncture in treatment on specific disorders). A majority of the documents on acupuncture are found in journals that can be classified as biomedical (general or specialized). However, over time it has become more common with publications in journals classified as Integrative and complementary medicine. As mentioned above, it is reasonable to relate this development to the fact that the category of Integrative and complementary journals has expanded during the couple of last decades. About 10 percent of the documents are published in what is defined as prestigious and high ranked journals with regard to Abridged Index Medicus/Core Clinical Journals and top 20, according to the general impact factor, in the category Medicine General \& Internal in Journal Citations Report.

An interesting part of the results is that there is a peak of publications in prestigious and high ranked journals in the middle of the time period, and a decrease in the total share at the end. Many of the most cited documents are also found in the categories of prestigious and highly ranked journals. When it comes to clinical trials on acupuncture it is also possible to identify a clear increase. The share of clinical trials in relation to all publications on acupuncture has evolved from two to five percent at the beginning of the period to 18-19 percent at the end. Most of the publications on acupuncture are from the US and China with 
25 and 14 percent for the whole time period, respectively. An interesting result is that there has been a shift between those two countries in terms of general publication activity, and that most publications during the last two years are from China. There is also a notable increase in the publication activity in South Korea. This pattern is also supported by the analysis of the regions. During the last couple of years the growth has been most notable in Asia.

\section{References}

Eisenberg, DM. et al. (1993) "Unconventional medicine in the united states - Prevalence, costs, and patterns of use", The New England Journal of Medicine, 328 (4):246-252.

Harris, P. \& Rees, R. (2000) "The prevalence of complementary and alternative medicine among the general population: a systematic review of the literature", Complementary Therapies in Medicine, (8): 88-96.

Adams, V. (2002) "Randomized controlled crime: Postcolonial sciences in alternative medicine research", Social Studies of Science, 32 (5-6):659-90.

Barnes J. et al. (1999) "Articles on Complementary Medicine in the Mainstream Medical Literature", Arcives of Internal Medicine, 159 (15):1721-1725.

Beer, TM. et al. (2010) "Acupuncture for hot flashes in patients with prostate cancer", Urology, 76 (5):1182-8.

Cant, S. \& Sharma, U. (1999) A New Medical Pluralism? Alternative Medicine, Doctors, Patients and the State. London: UCL Press.

Danell, JAB. \& Danell R. (2009) "Publication activity in complementary and alternative medicine", Scientometrics, 80 (2): 539-551.

Easthope. G. (2003) "Alternative, Complementary, or Integrative?", Complementary Therapies in Medicine, 11 (1):2-3.

Fontanarosa, PB. (2001) "Publication of Complementary and Alternative Medicine Research in Mainstream Biomedical Journals", The Journal of Alternative and Complementary Medicine. 7 (supplement 1):139-143.

$\mathrm{Fu}$, JY. et al. (2011) "Bibliometric analysis of complementary and alternative medicine research over three decades", Scientometrics, Forthcoming. DOI: 10.1007/s11192011-0391-0

Gorski, T. (1996) "Defining and Assessing Alternative Medicine Practices" JAMA - Journal of the American Medical Association, 276 (3):195-196.

Han, JS. \& Ho, YS. (2011) "Global trends and performances of acupuncture research", Neuroscience and Biobehavioral Reviews. 35 (3):680-7.

Jütte, R. (2001) “Alternative Medicine and Medico-Historical Semantics” in Jütte, R. , Eklöf, M. \& Nelson, M. C. [ed.] (2001) Historical Aspects of Unconventional Medicine Approaches, Concepts, Case Studies. Sheffield: European Association for the History of Medicine and Health Publications.

Kim YC. et al. (2004) "An examination of the relationship between five oriental musical tones and corresponding internal organs and meridians", Acupuncture $\mathcal{E}$ Electrotherapy Research, 29 (3-4):227-33.

Lansdown, H. et al. (2009) "Acupuncture for pain and osteoarthiris of the knee: a pilot study for an open parallel-arm randomized controlled trial", BMC Muscoskeletal Disorders, 10:130. 
Mazetto MO. et al. (2007) “Low intensity laser application in temporomandibular disorders: a phase I double blind study", Cranio, 25 (3):186-92.

Singh BB. et al. (2008) "Influence of comorbidities on improvement of fibromyalgia symptoms when treated with acupuncture: a short report", Alternative Therapies in Health and Medicine, 14 (5):24-5.

Thomas KJ. et al. (2001) "Use and expenditure on complementary medicine in England: a population based survey", Complementary Therapies in Medicine, 9 (1):2-11.

Vickers, AJ. et al. (2004) "Acupuncture for postchemptherapy fatigue: a phase II study", Journal of Clinical Oncology, 1:22 (9):1731-5.

Wong, RK. et al. (2003) "A phase II study in the use of acupuncture-like transcutaneous nerve stimulation in the treatment of radiation-induced xerostomia in head-andneck cancer patients treated with radical radiotherapy", International Journal of Radiation Oncology Biology Physics, 1:57 (2):472-80.

Zeltzer LK. et al. (2002) "A Phase I study on the feasibility and acceptability of acupuncture/hypnosis intervention for chronic pediatric pain", Journal of Pain and Symptom Management, 24 (4):437-46.

Vincent, C. \& Furnham, A. (1996) "Why do patients turn to complementary medicine? An empirical study", British Journal of Clinical Psychology, 35 (1):37-48.

Thomas, KJ. et al.(2001) "Use and expenditure on complementary medicine in England: a population-based survey", Complementary Therapies in Medicine, 9 (1): 2-11. 


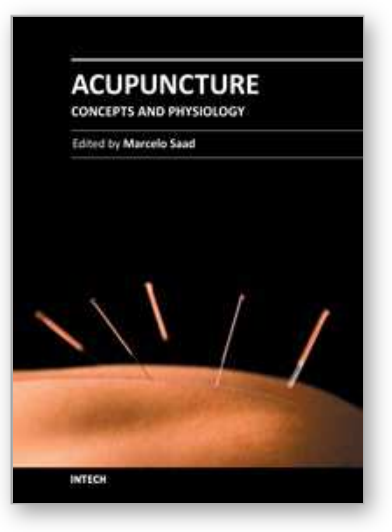

\author{
Acupuncture - Concepts and Physiology \\ Edited by Prof. Marcelo Saad
}

ISBN 978-953-307-410-8

Hard cover, 222 pages

Publisher InTech

Published online 10, October, 2011

Published in print edition October, 2011

Acupuncture and related techniques are useful tools for treating a spectrum of diseases. However, there are still many areas of controversy surrounding it. We hope this book can contribute to guide the advance of this ancient medical art. In the present work, the reader will find texts written by authors from different parts of the world. The chapters cover strategic areas to collaborate with the consolidation of the knowledge in acupuncture. The book doesnâ€ TMt intend to solve all the questions regarding this issue but the main objective is to share elements to make acupuncture more and better understood at health systems worldwide.

\title{
How to reference
}

In order to correctly reference this scholarly work, feel free to copy and paste the following:

Jenny-Ann Brodin Danell and Rickard Danell (2011). Development of Scientific Publications on Acupuncture, Acupuncture - Concepts and Physiology, Prof. Marcelo Saad (Ed.), ISBN: 978-953-307-410-8, InTech, Available from: http://www.intechopen.com/books/acupuncture-concepts-and-physiology/development-ofscientific-publications-on-acupuncture

\section{INTECH}

open science | open minds

\section{InTech Europe}

University Campus STeP Ri

Slavka Krautzeka 83/A

51000 Rijeka, Croatia

Phone: +385 (51) 770447

Fax: +385 (51) 686166

www.intechopen.com

\section{InTech China}

Unit 405, Office Block, Hotel Equatorial Shanghai

No.65, Yan An Road (West), Shanghai, 200040, China

中国上海市延安西路65号上海国际贵都大饭店办公楼 405 单元

Phone: +86-21-62489820

Fax: +86-21-62489821 
(C) 2011 The Author(s). Licensee IntechOpen. This is an open access article distributed under the terms of the Creative Commons Attribution 3.0 License, which permits unrestricted use, distribution, and reproduction in any medium, provided the original work is properly cited. 